\title{
Pancreatic Somatostatin Secretion is Suppressed by Splanchnic Nerve Stimulation
}

\author{
M. W. Roy, M. S. Jones, and R. E. Miller \\ Department of Pharmacology, University of Kentucky College of Medicine, Lexington, Kentucky, USA
}

\begin{abstract}
Summary. The pancreases of fasted mongrel puppies $(n=4)$ were isolated and perfused in a non-recirculating system with an oxygenated Krebs Ringer bicarbonate buffer. The gland remained in situ and innervated. Bilateral stimulation of the splanchnic trunks $(20 \mathrm{~V}, 5 \mathrm{~Hz}, 1 \mathrm{msec})$ resulted in a significant decrease in somatostatin $(57 \pm 10 \%, \mathrm{p}<0.01)$ and insulin $(71 \pm 3 \%, p<0.01)$, secretion rates, together with a significant increase in pancreatic perfusion pressure $(53 \pm 6 \%, \mathrm{p}<0.05)$. Perfusate glucose concentration remained constant during stimulation. No difference was found between three, three minute stimulations in any one dog, but significant differences were found among the dogs in the prestimulation somatostatin secretion rate in spite of the similarities in the buffer glucose concentration.
\end{abstract}

Key words: Somatostatin, splanchnic nerves, perfused dog pancreas, insulin

Somatostatin, a tetradecapeptide, discovered in the hypothalamus [1] and later identified in the D cells of the pancreatic islets [2], has been shown to inhibit many important metabolic processes, including the secretion of insulin and glucagon (for review see [3]). Study of the stimuli which release somatostatin from the pancreas may contribute to an understanding of its physiological role. Schauder et al. [4] demonstrated increased release of somatostatin from isolated islets stimulated by glucose or theophylline. Ipp et al. [5], using the perfused canine pancreas, reported that a number of intestinal hormones caused a somatostatin secretory pattern similar to that of insulin.

The effects of splanchnic nerve stimulation on pancreatic somatostatin secretion have not been reported, but evidence suggests that such stimulation may alter somatostatin release. Other pancreatic hormones, insulin, glucagon and pancreatic polypeptide, are influenced by stimulation of the autonomic nerves $[6,7,8,9]$. Infusion of neurotransmitters and their antagonists directly into the pancreatic arterial circulation alters the amount of somatostatin secreted [10].

In the present study, we examined the effect of splanchnic nerve stimulation on the secretion of immunoreactive somatostatin from the isolated, buffer perfused canine pancreas.

\section{Materials and Methods}

Experiments were conducted with four chloralose-anaesthetized male or female mongrel puppies $(3-6 \mathrm{~kg}$ ) which had been fasted for 15 hours prior to the experiments. Following anaesthesia, the animals were maintained on positive pressure respiration with room air.

\section{Surgery}

Catheters (PE100, Clay Adams) were introduced into the right femoral artery and vein for blood pressure determination and for administration of anaesthetic. The abdomen was opened with a cruciform incision using electrocautery. The caudal mesenteric artery was tied and a splenectomy performed. The common bile duct and all branches of the coeliac axis, except the superior pancreaticoduodenal artery and the splenic artery were ligated. The coeliac axis and the cranial mesenteric artery were isolated by carefully dissecting the connective tissue and nerves away from the vessels near their aortic origins. All of its branches, as well as the distal portion of the cranial mesenteric artery itself, except the inferior pancreaticoduodenal branch, were ligated. The pancreas was separated from the duodenum by ligation of the arterial twigs between the two organs. Sutures were passed around the oesophagus and pylorus and tied. Perfusion was begun by catherization of the celiac axis and cranial mesenteric artery with flanged catheters (PE190, Clay Adams) through which oxygenated buffer (see below) was flowing. 


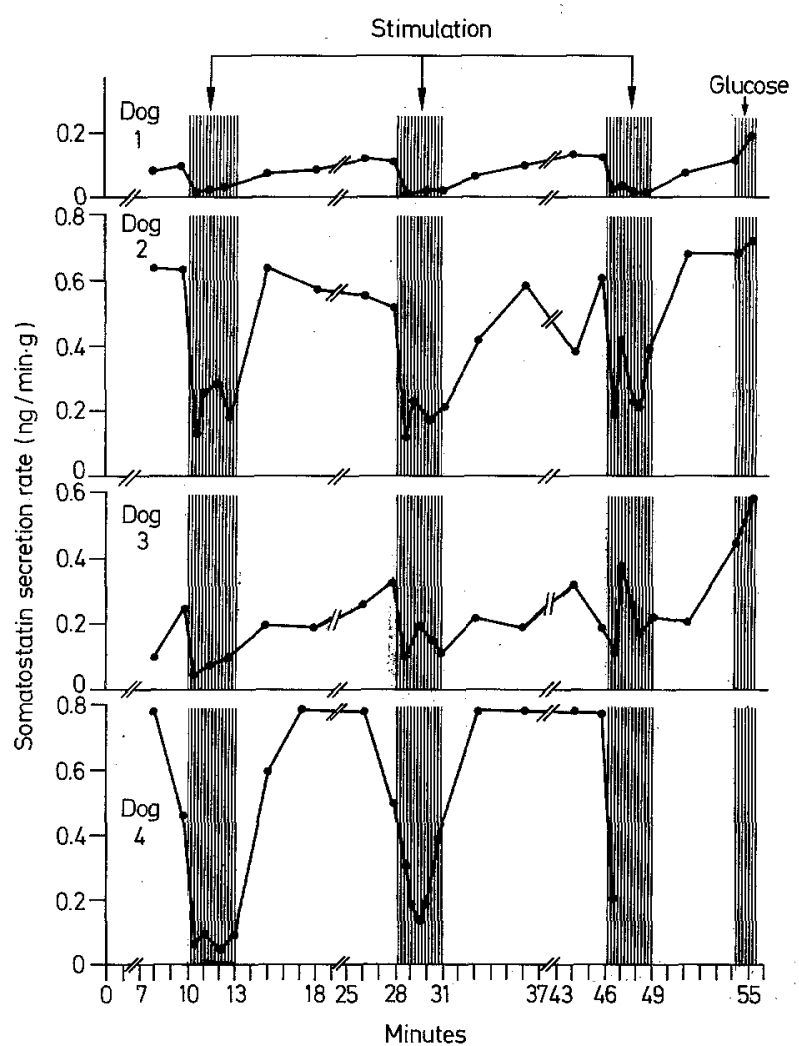

Fig. 1. Effect of splanchnic nerve stimulation on somatostatin secretion rate by dog pancreas. Results from 4 dogs are shown. Somatostatin secretion rate was calculated at each point as the product of the effluent somatostatin concentration and the buffer flow rate, divided by the wet weight of the pancreas

The portal vein was catherized (PE260, Clay Adams) approximately $1 \mathrm{~cm}$ cranial to the entrance of the pancreaticoduodenal vein. Negative pressure was maintained in the portal vein by placing the free end of the catheter $50-75 \mathrm{~cm}$ below the vein.

The main splanchnic trunks were isolated bilaterally and fitted with fluid filled electrodes [11] and each animal was placed in a plexiglass box (Vanderbilt Instrumentation Shop, Vanderbilt University, Nashville, Tenn.) automatically maintained at $38^{\circ} \mathrm{C}$. Blood pressure, body temperature, plasma glucose, pancreatic perfusion pressure, and pancreatic temperature were monitored throughout each experiment.

\section{Perfusate}

The perfusate was a Krebs-Ringer bicarbonate buffer. It contained (in $\mathrm{g} / 1$ ) $\mathrm{NaCl} 7.6, \mathrm{KCL} 0.25, \mathrm{KH}_{2} \mathrm{PO}_{4} 0.15, \mathrm{MGSO}_{4} 0.18$, $\mathrm{NAHCO}_{3} 2.05, \mathrm{CaCl}_{2} 0.29$ [all salts Sigma Reagent grade, Sigma Chem. St. Louis, MO.], to this solution was added 2.0 grams per liter bovine serum albumin (Sigma Franction V), $33 \mathrm{~g} / 1$ dextran (Sigma Clinical grade M.W. 70.000 ), and $13.0 \mathrm{~g} / 1$ of glucose ( 7.2 mmole/l) (glucose Invenex, Chagrin Falls, OH.). The $\mathrm{pH}$ of the buffer entering the pancreas was 7.4. The buffer was oxygenated with $95 \% \mathrm{O}_{2}, 5 \% \mathrm{CO}_{2}$.

\section{Experimental}

After a $15 \mathrm{~min}$ equilibration period, the response to bilateral splanchnic nerve stimulation $(5 \mathrm{~Hz}, 20$ Volts, $1 \mathrm{msec})$ was tested prior to the beginning of the experimental protocol. Stimulation was deemed satisfactory when a rise of at least $25 \mathrm{mmHg}$ in the perfusion pressure occurred immediately after stimulation commenced. The actual experimental protocol consisted of 3, 3 min bilateral splanchnic nerve stimulations $15 \mathrm{~min}$ apart (Fig. 1). Before, during and after each stimulation, samples were collected for 15 seconds in graduated tubes for flow determination and assay. Hormone secretion rates were calculated as the products of flow and concentration. At the end of each experiment, the insulin secretory response of each pancreas was tested by a pancreatic arterial infusion of glucose sufficient to raise the buffer concentration to $300 \mathrm{mg} / \mathrm{dl}$. Samples were frozen in polyethylene tubes for measurement of insulin, glucose and somatostatin (collected with aprotinin, $500 \mathrm{KIU} / \mathrm{ml}$ of sample). Immunoreactive insulin [12] and somatostatin (kit purchased from Immuno Nuclear, Inc. P.O. 285, Stillwater, MN. 55082) were assayed by double antibody techniques. The somatostatin antiserum was reported, by the company, to show no cross reactivity with beta endorphin, substance $P$, leucine enkephalin, methionine enkephalin, arginine vasopressin, leucine vasopressin, oxytocin, LHRH, insulin, glucagon, glucose, $\mathrm{TRH}$, or VIP. In our laboratory, we found that the somatostatin antiserum did not cross react with pancreatic polypeptide, VIP, or TRH. The intra-assay coefficient of variation was $8 \%$, and the interassay coefficient of variation was $9.5 \%$. The assay was able to detect $16-32 \mathrm{pg} / \mathrm{ml}$ of somatostatin as being significantly different from 0 with $95 \%$ confidence.

We found recovery of known amounts of somatostatin comparable when they were added to pancreatic effluent samples which were collected before, during and after nerve stimulation. Thus nerve stimulation did not enhance somatostatin breakdown in the pancreatic effluent.

Insulin secretion rate (ISR) and somatostatin secretion rate (SSR) were calculated as the product of the effluent hormone concentration and the buffer flow. Glucose was assayed with an automated glucose-oxidase technique (Yellow Springs Instruments [13]). Experiments were chosen for somatostatin assay only if the ISR decreased and the blood perfusion and pressure increased during splanchnic nerve stimulation (Table 1). All experiments in which somatostatin was assayed are reported. The mean integrated somatostatin secretion rate ( $\overline{\mathrm{SSR}})$ and the mean integrated insulin secretion rate ( $\overline{\mathrm{ISR}})$ were calculated as the areas under the secretion rate curves. The areas before and during stimulation were compared by a sign test and an analysis of variance [14]. In Table 1, comparisons were made by Student's paired t-test.

\section{Results}

As shown in Figure 1, the SSR decreased immediately in every stimulation $(\mathrm{p}<0.01)$. The analysis of variance of the $\overline{\mathrm{SSR}}$ demonstrated a decrease in the $\overline{\text { SSR }}$ with nerve stimulation $(\mathrm{p}<0.01)$, a difference between dogs in the $\overline{\text { SSR }}(\mathrm{p}<0.01)$, and no difference between successive nerve stimulations in any single dog. Changes in ISR $(p<0.01)$, perfusion pressure $(\mathrm{p}<0.05)$, mean arterial pressure $(\mathrm{p}<$ 0.01 ), and buffer glucose concentration during stimulation and after glucose infusion are shown in Table 1. The only significant change in buffer glucose occurred during the pancreatic arterial injection of glucose which was made to test the insulin response $(\mathrm{p}<$ 0.01 , see glucose injection, Table 1) at the end of each experiment. 
Table 1. Average values determined for the 2 min before (pre), the three min during (stim) and the 5 min after (post) bilateral splanchnic nerve stimulation. The basal somatostatin secretion rates $(\mathrm{n}=4)$ were (in $\mathrm{ng} / \mathrm{min}$.g pancreas) $0.09,0.63,0.21$, and 0.59 for the two $\mathrm{min}$ prior to nerve stimulation. Splanchnic nerve stimulation elicited significant changes during all 3 stimulations in immunoreactive somatostatin $(p<0.01)$, insulin secretion rate $(p<0.01)$, pancreatic perfusion pressure $(p<0.05)$, pancreatic effluent flow $(p<0.01)$ and mean arterial pressure $(\mathrm{p}<0.05)(\mathrm{n}=4$, paired $\mathrm{t}$-test $)$. The only significant change in buffer glucose $(\mathrm{p}<0.01)$ occurred after the pancreatic arterial glucose injection used to test the insulin secretory response at the end of each experiment

\begin{tabular}{|c|c|c|c|c|c|c|c|c|c|c|c|}
\hline & & \multicolumn{3}{|c|}{ Stimulation 1} & \multicolumn{3}{|c|}{ Stimulation 2} & \multicolumn{3}{|c|}{ Stimulation 3} & \multirow{2}{*}{$\begin{array}{l}\text { Glucose } \\
\text { injection }\end{array}$} \\
\hline & & pre & stim & post & pre & stim & post & pre & stim & post & \\
\hline \multirow{2}{*}{$\begin{array}{l}\text { Immunoreactive } \\
\text { somatostatin ( } \% \text { basal) }\end{array}$} & mean & 100 & 39 & 116 & 115 & 58 & 106 & 111 & 59 & 78 & 280 \\
\hline & SEM & - & 13 & 16 & 17 & 19 & 10 & 11 & 15 & 12 & 90 \\
\hline \multirow{2}{*}{$\begin{array}{l}\text { Insulin secretion } \\
\text { rate (ng/min.g) }\end{array}$} & mean & 0.79 & 0.22 & 0.78 & 0.88 & 0.23 & 0.87 & 0.94 & 0.27 & 0.94 & 8.11 \\
\hline & SEM & 0.06 & 0.09 & 0.06 & 0.13 & 0.13 & 0.07 & 0.02 & 0.03 & 0.07 & 1.35 \\
\hline \multirow[t]{2}{*}{ Glucose (mg/dl) } & mean & 125 & 125 & 126 & 125 & 127 & 124 & 126 & 126 & 126 & 297 \\
\hline & SEM & 5 & 4 & 4 & 4 & 4 & 3 & 5 & 4 & 5 & 17 \\
\hline \multirow{2}{*}{$\begin{array}{l}\text { Perfusion pressure } \\
\text { (mmHg) }\end{array}$} & mean & 124 & 201 & 118 & 120 & 183 & 116 & 124 & 179 & 119 & 122 \\
\hline & SEM & 4 & 18 & 6 & 4 & 10 & 5 & 3 & 10 & 3 & 6 \\
\hline \multirow[t]{2}{*}{ Flow \% basal } & mean & 100 & 79 & 94 & 101 & 81 & 96 & 98 & 83 & 97 & 98 \\
\hline & SEM & - & 9 & 10 & 6 & 10 & 9 & 7 & 8 & 7 & 5 \\
\hline \multirow{2}{*}{$\begin{array}{l}\text { Mean arterial } \\
\text { pressure }(\mathrm{mmHg})\end{array}$} & mean & 66 & 89 & 60 & 63 & 86 & 63 & 59 & 84 & 61 & 60 \\
\hline & SEM & 8 & 9 & 9 & 6 & 7 & 5 & 4 & 6 & 3 & 5 \\
\hline
\end{tabular}

\section{Discussion}

Splanchnic nerve stimulation is accompanied by a decreased $\overline{\mathrm{SSR}}$. The decrease in $\overline{\mathrm{SSR}}$ is associated with significant decreases in concentration as well as flow (Table 1). It seems, therefore, that splanchnic nerve stimulation decreases $\overline{\mathrm{SSR}}$ by an interaction with the islet cells as well as an action on the pancreatic vasculature.

Decreased ISR and increased perfusion pressure with splanchnic nerve stimulation confirm previous work in this laboratory [6]. Since phentolamine has been shown to block this sympathetically induced suppression of the ISR [6], the decreased ISR and SSR demonstrated in the present study may be explained by activation of post-synaptic adrenergic receptors. Support for this hypothesis comes from Samols and Weir [10] who found that $\alpha$ adrenergic agonism, generated by infusing epinephrine plus propranalol, decreased somatostatin secretion. The decrease was blocked by phenoxybenzamine. The present study does not exclude the possibility that the observed decrease is mediated by cholinergic or peptidergic transmitters.

The observed differences in SSR among dogs, despite the small variance in the buffer glucose concentration, is similar to that found by Samols and Weir [10]. This interesting finding is currently not explained.

Autonomic nerves have previously been shown to evoke alterations in the secretory rate of insulin, glucagon, and pancreatic polypeptide. The present study indicates that the SSR is influenced by splanchnic nerve stimulation. Since vagal stimulation increased antral luminar SSR [15] and decreased portal vein somatostatin concentration [16] it appears that intestinal somatostatin is subject to alterations by the parasympathetic nerves. We conclude that enteric somatostatin secretion is influenced by the autonomic nervous system, supporting the contention that neural mechanisms play a role in the regulation of somatostatin as well as the other hormones of the endocrine pancreas.

Acknowledgement. Mr. Roy is supported by a Graduate Student Fellowship from the Isbell Kircher Fund.

The authors gratefully acknowledge Dr. Sami F. Said of the V. A. Medical Center, Dallas and Dr. R. E. Chance of Eli Lilly in Indianapolis for their gifts of TRH and pancreatic polypeptide and Ms. Diane Emerson for her manuscript typing.

\section{References}

1. Brazeau P, Vale W, Burgus R, Ling N, Butcher M, Rivier J, Guillemin R (1973) Hypothalamic polypeptide that inhibits the secretion of immunoreactive pituitary growth hormone. Science 179: 77-79

2. Luft R, Efendic S, Hokfelt T, Johansson O, Arimura A (1974) Immunohistochemical evidence for the localization of somatostatin-like immunoreactivity in a cell population of the pancreatic islets. Med Biol 52: 428-430

3. Brown M, Vale, W (1978) Somatostatin: Five years of progress. Biomedicine 28: 93-96

4. Schauder, P, McIntosh C, Arends, J, Arnold R, Frerichs, H, Creutzfeldt W (1976) Somatostatin and insulin release from isolated rat pancreatic islets stimulated by glucose. FEBS Lett 68: $225-227$ 
5. Ipp E, Dobbs RE, Harris V, Arimura A, Vale W, Unger RH (1977) The effects of gastrin, gastric inhibitory polypeptide, secretin, and the octapeptide of cholecystekinin upon immunoreactive somatostatin release by the perfused canine pancreas. J Clin Invest 60: 1216-1219

6. Miller RE (1975) Neural inhibition of insulin secretion from the isolated canine pancreas. Am J Physiol 229: 144-149

7. Miller RE, Horton ES (1979) Neural release of glucagon is inhibited by hyperglycemia and enhanced by phentolamine. Diabetes 28: 762-768

8. Taylor FL, Impicciatore M, Carder DC, Walsh JH (1978) Effect of atropine and vagotomy on pancreatic polypeptide response to a meal in dogs. Am J Physiol 235: E443-E447

9. Bloom SR, Edwards AF (1978) Certain pharmacological characteristics of the release of pancreatic glucagon in response to stimulation of the splanchnic nerves. J Physiol (Lond) 280: 9-23

10. Samols E, Weir GC (1979) Adrenergic modulation of pancreatic A, B, and D cells. J Clin Invest 63: 230-238

11. Porter EL, Allamon EL (1936) Barbiturate-strychnine antagonism in the spinal cat: A quantitative study. J Pharmacol Exp Ther 58: 178-191

12. Morgan CR, Lazarow A (1963) Immunoassay of Insulin: Two antibody system plasma insulin levels of normal, subdiabetic, and diabetic rats. Diabetes 12: 115-126
13. Clark LC Jr (1973) A polarographic enzyme electrode for the measurement of oxidase substances. In: Kessler M (ed) Oxygen supply. Urban \& Schwarzenberg, München Berlin Wien, p 120-128

14. Snedecor GW, Cochran WG (1967) Statistical methods, 6th ed. Iowa State University Press, Ames, Iowa

15. Uvnas-Wallenstein K, Efendic S, Luft R (1978) The occurrence of somatostatin-like immunoreactivity in the vagal nerves. Acta Physiol Scand 102: 247-250

16. Efendic S, Long PE, Luft R (1978) Somatostatin and insulin secretion. Metabolism 27: 1275-1281

Received: January 23, 1980 ,

and in revised form: April 23, 1980

Dr. Ralph E. Miller

Department of Pharmacology

MR-124 Research Facility \#2

University of Kentucky

Lexington, KY 40536

USA 